\section{Humane Education: A Paradigm for Ethical Problem Solving in Education}

\author{
Joyce L. Bloom \\ Bronx Community College
}

This article is dedicated to $\mathrm{Mr}$. Walter $\mathrm{C}$. Edge, Executive Deputy Superintendent of Community School District 12, New York City, for his distinguished educational leadership and support of humane education.

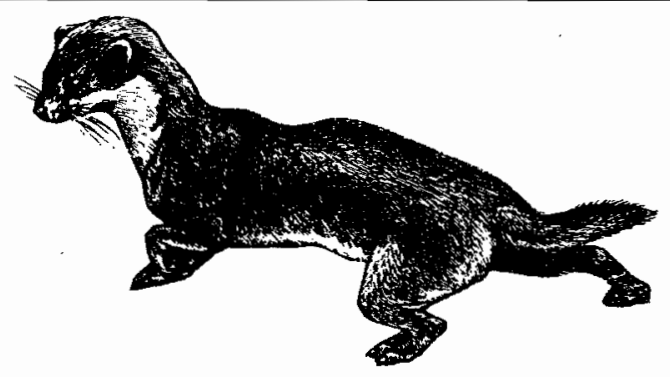

What is right? What is wrong? In modern education it is often impossible to achieve single answers to this very difficult question, particularly in the current climate of increasing societal metamorphosis. It is difficult to teach or even discern an ethical answer to a question in this modern age. Factors of social change include issues such as those related to the structure of the family, the technologization of the world of work, escalating inflation, economic interdependence with foreign nations, local versus state versus federal control of education, world peace issues, and other factors. It is a highly complicated matter to formulate and implement ethical decisions and policies against the background of such pervasive societal change.

In this context three specific concepts necessarily come into focus for educators. The first deals with people, the second with the school as an institution, and the third with basic intrinsic values.

First, the concept of morality that educators as people bring to education needs to be considered. How do we approach the idea of morality? What constitutes "goodness"? What is ethical behavior?

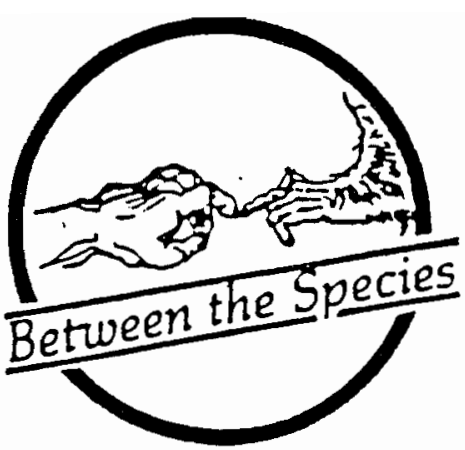

What is our philosophical system to solve ethical questions? We frequently encounter ethical problems in our profession. How do we formulate ethical answers to these problems?

Second, the concept of the school as a social institution comes into focus. That is, how shall the school with its goals, its curriculum, its staff, its schedule, and other components be organized and administered to serve the public ethically? What policies, procedures and choices should be made in order to be not just effective and efficient, but ethical as well?

Third, the concept of basic intrinsic values needs to be addressed. In large measure, this is central to education. What basic values do we want to impart to students? What values are desirable and ethical of their own account? Further, what experiences and resources are necessary to educate students to these values? Are these experiences appropriate for all students in similar circumstances? How do we internalize ethics and discipline and motivation? How do we measure outcomes of these experiences with respect to individual students, whole classes, institutions on various levels, and entire school systems?

The purpose of this article is to propose humane education as a paradigm for ethical problem solving in education, from both the curriculum and administrative perspectives. The paradigm is four-dimensional and may be conceptualized as follows:

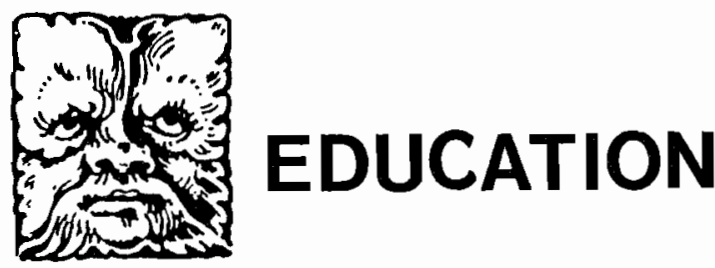




\section{Paradigm for Ethical Problem Solving}

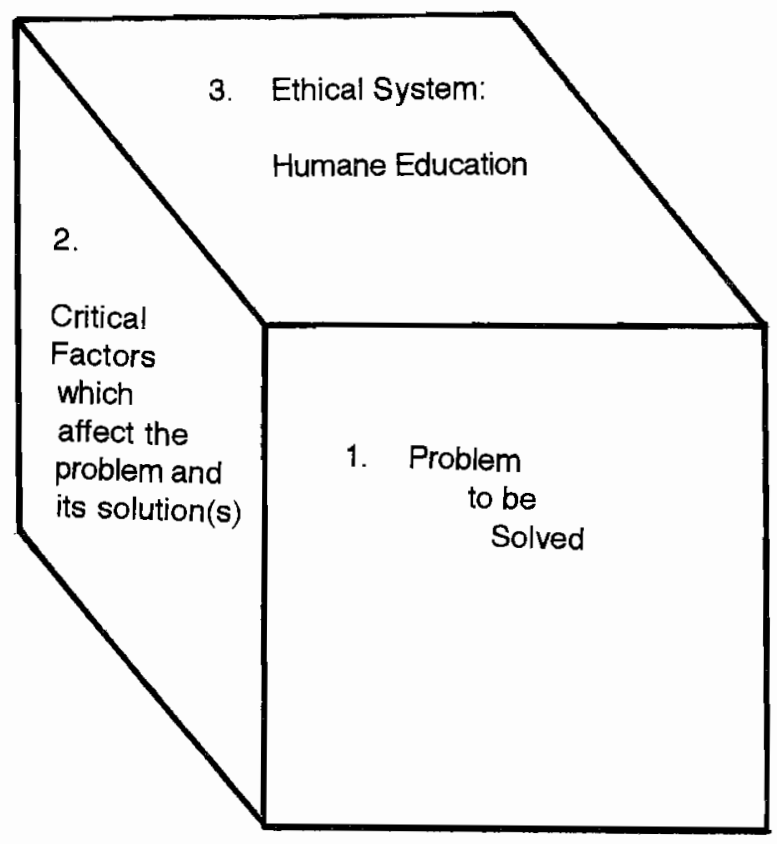

4

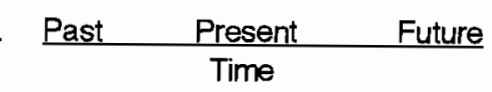

As can be readily seen, humane education is central to this model. Salient principles, particularly of respect for all nature and life, consideration and thought for other persons, kindness to all, and the reciprocity inherent in the golden rule are essential. The model is useful in that it assists in identifying and clarifying the problem as well as in discovering and testing possible solutions to the problem. The model can be applied to curriculum or to administrative concerns.

In the curriculum, the model can be applied to humane education itself or to other areas. For example, a topic selected in humane education such as, "What should be done with stray dogs and cats?," can be solved by using the model. First, the problem is identified, including eliciting stories and impressions from students regarding the incidence of the problem. Second, critical factors such as the domestication of pet animals and their inability to survive and thrive in modern society without the intervention of people, the reproductive cycles of pet animals, and the related health problems of strays, etc. over time are listed. Third, students may propose and evaluate short- and long-range solutions in light of humane education principles.

The dimension of time can assist in assessing the proposed solutions from both short- and long-range vantage points.

Likewise, the model may be applied to a curriculum area other than humane education, thereby infusing the principles of humane education into that curriculum. For example, a topic in social science, specifically, history may addressed by matching relevant aspects to the model. Typical questions may be looked at such as, what factors precipitated a particular event, what was the significance of this event, or what were the negative versus the positive outcomes of the event? The situation in its historical context may be researched including the personalities and politics involved and other features of the times. The background of the problem can then be viewed by looking at, considering and discussing various elements uncovered in the research. The factors leading up to a particular event may then be juxtaposed with humane education principles and further discussed to make ethical judgments about the event. The popular question, "Should World War II have been fought?," may be used. The predisposing fact to World War II can be researched and the pros and cons of the question perused in light of ethical or humane education considerations. Thus, the model may be useful in teaching curriculum areas to students and in developing their critical thinking skills.

The model may also be applied to the practice of educational organization in administration to assist administrators and supervisors in their work. Cases in point abound. Questions, such as, what can we do for children with problems which interfere with their learning, how do we allocate our limited resources, how do we organize the day to best serve all of our students, how do we evaluate teachers, what are our policies about violent student behavior, and a myriad of other such issues confront administrators on a daily basis. Clear cut sole solutions may not exist for each problem; however, a more balanced perspective may be achieved by applying humane education principles to the problems.

A model can be beautiful particularly if it is complete and helps to advance our ability to do the work that needs to be done to enhance each individual and society. 
Humane education, so consistent with the precepts of democracy and overall education in the United States of America, is a suitable looking glass to hold proposed solutions to ethical questions against. We as educators need to decide how we will meet this challenge. To paraphrase Albert Schweitzer, perhaps the greatest humane educator, who has contributed philosophic works on the relation of moral ethics and civilization, affirming "the true goodness which requires us to respect the lives of all creatures." This is truly the foundation upon which we must build.

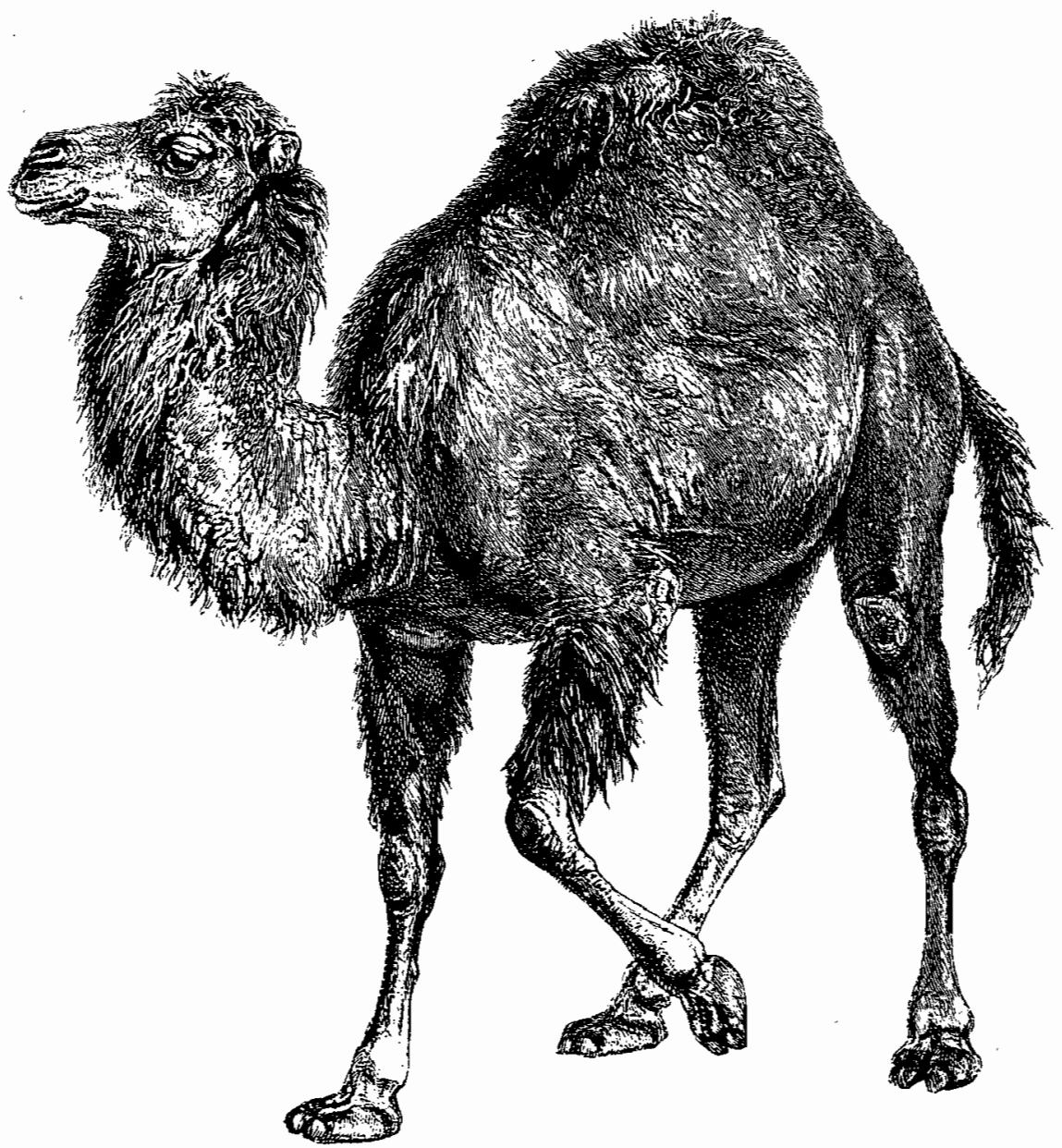

